\title{
Arazi Fiyatını Etkileyen Faktörlerin Doğrudan ve Dolaylı Etkilerinin Path Analizi ile Belirlenmesi: Samsun İli Ladik İlçesi Örneği
}

\author{
Uğur BAŞER ${ }^{*}$, Osman KILIÇ ${ }^{1}$, Hasan Samet ABACI ${ }^{2}$ \\ ${ }^{1}$ Ondokuz Mayıs Üniversitesi, Ziraat Fakültesi, Tarım Ekonomisi Bölümü, Samsun, TÜRKIYE \\ ${ }^{2}$ Ondokuz Mayls Üniversitesi, Ziraat Fakültesi, Zootekni Bölümü, Samsun, TÜRKIYYE
}

\begin{tabular}{ll}
\hline \multicolumn{1}{c}{ Geliş Tarihi/Received: 03.08.2018 } & Kabul Tarihi/Accepted: 22.02.2019 \\
\hline ORCID ID (Yazar surasina göre / by author order) & \\
\hline Dorcid.org/0000-0003-4961-2764 (D) orcid.org/0000-0002-0129-4034 & (D) orcid.org/0000-0002-1341-4056 \\
\hline "Sorumlu Yazar/Corresponding Author: ugur.baser@omu.edu.tr &
\end{tabular}

Öz: Araştırmanın amacı, arazi fiyatını etkileyen faktörlerin doğrudan ve dolaylı etkilerini belirlemektir. Araştırmanın materyalini, 2018'de Samsun ili Ladik ilçesinde yapılan anketler oluşturmaktadır. Araştırmada, arazi fiyatını doğrudan ve dolaylı etkileyen faktörler path analiziyle ortaya konulmuștur. Araştırma sonuçlarına göre; arazi fiyatını pozitif yönde etkileyen değişkenler verim ve sulama iken, negatif yönde etkileyen değişkenler taşlılık, eğim, köye ve ana yola uzaklıktır. Arazi fiyatını doğrudan etkileyen en önemli değişken \% 60 ile ana yola uzaklık, en yüksek dolaylı etkiye sahip değişken ise \% 69 ile taşlılık durumudur. Arazi fiyatını pozitif yönde etkileyen verimin doğrudan etkisi \% 44, dolaylı etkisi \% 56' dır. Sulamanın ise doğrudan etkisi \% 38, dolaylı etkisi \% 62'dir. Sulamaya ait dolaylı etkinin \% 45'i sulamanın ürün verimini artırmasından kaynaklanmaktadır. Arazi fiyatını etkileyen faktörlerin doğrudan ve dolaylı etkilerinin ortaya konulması, bilimsel ve objektif arazi değerleme çalışmalarına önemli katkı sağlayacaktır. Ayrıca elde edilen sonuçlar, arazi değerleme yöntemleri için yardımcı bir unsur olarak kullanılabilecektir.

Anahtar Kelimeler: Arazi değerleme, arazi fiyatı, path analizi

\section{Determining Direct and Indirect Effects of the Factors Influencing Land Price by Path Analysis: A Case Study of Ladik District-Samsun}

\begin{abstract}
The aim of this study was to determine the direct and indirect effects of factors affecting land prices. The data of the study were collected through questionnaires in Ladik District of Samsun Province, Turkey in 2018. In the study, the factors that directly and indirectly affected the price of land were determined by using path analysis. While the factors that affected land price positively were yield and irrigation, the factors that affected land price negatively were stoniness, slope and distance from village and main road. The most important variable that affected land price directly was the distance from the main road $(60 \%)$, the variable that most affected land price indirectly was stony soil $(69 \%)$. The direct effect of yield on the land price was $44 \%$ and the indirect effect was $56 \%$. The direct effect of irrigation was $38 \%$ and the indirect effect was $62 \%$. The study also determined that $45 \%$ of the indirect effect of irrigation was due to increased productivity. Explaining the direct and indirect effects of the factors affecting the land price will make a significant contribution to scientific and objective land valuation studies. In addition, the results obtained can be used as an auxiliary element for land valuation methods.
\end{abstract}

Keywords: Land valuation, land price, path analysis 


\section{Giriş}

Üretim faktörlerinden biri olan arazi; toprak, iklim, topografya ve canlıların değişik oranda etkisi altında bulunan yeryüzü parçasını ifade etmektedir. Çoğaltma olanağı olmayan tek üretim aracı olan arazi, bitkisel üretimin yanı sıra; büyükbaş ve küçükbaş hayvancılık, arıcılık, seracılık gibi birçok faaliyetle insanların geçimini sağladığı yerdir. Arazi, aynı zamanda birçok insan için yatırım alanı ve güvence kaynağı olarak görülmektedir (Başer, 2015).

Türkiye'de kamu ve özel sektör tarafindan yapılan altyap1 ve üstyapı yatırımları nedeniyle, kamulaştırma uygulamaları başta olmak üzere toplulaştırma çalışmaları, arazinin imara açılması ve sulama projeleri gibi birçok konu arazi fiyatıyla yakından ilgilidir. Aynı zamanda banka teminatları ve vergilendirme gibi uygulamaların arazi fiyatıyla ilgili olması, arazi değerleme konusundaki araştırmaların önemini artırmaktadır.

Değerleme; tarım işletmeleri, işletme parselleri ile diğer kırsal mal ve hakların değerlerinin tam ve doğru olarak ortaya konulması olarak tanımlanmaktadır (Rehber, 2012). Arazi değerleme uygulamalarında yaygın olarak emsal karşılaştırma ve gelir yöntemleri kullanılmaktadır. Türkiye'de kamulaştırma kapsamındaki taşınmaz mallarda değerleme işlemleri, Kamulaştırma Kanunu'nca belirtilen esaslar çerçevesinde, kamu kurumlarında oluşturulan kıymet takdiri komisyonları ve mahkemenin görevlendirdiği bilirkişiler tarafindan yapılmaktadır. Uygulamada yasal düzenleme ve bilimsel yaklaşımlardan ziyade, genellikle kişisel kanıya dayalı kıymet takdiri yapıldığı ve yanlış değerlendirme unsurlarının esas alındığ görülmektedir (Kılıç, 2011). Türkiye'de Kamulaștırma Kanunu'nun 11'inci maddesinin f bendinde, "arazilerde, taşınmaz mal veya kaynă̆ın mevkii ve şartlarına göre ve olduğu gibi kullanılmast halinde getireceği net gelirin" esas alınması gerektiği ifade edilmektedir (Anonim, 1983). Gelirin kapitalizasyonu yaklaşımına göre tarım arazisinin değeri, o araziden gelecekte elde edileceği varsayılan net gelirin, bugüne kapitalize edilmesi esasına dayanmaktadır (Kılıç, 2011). Ancak bu yaklaşımla, araziye ait fiziksel ve konumsal bir takım özelliklerin fiyata etkisi ölçülememektedir. Son y1llarda araziye ait özelliklerin, arazi fiyatı üzerine etkisini ortaya koymak için ileri istatistiki yöntemlerin kullanıldı̆̆ modeller geliştirilmiştir (Isgin ve Forster, 2006; Hurma, 2007; Kuethe ve ark., 2011; Öztürk Coşar ve Engindeniz, 2013; Sklenicka ve ark., 2013; Borchers ve ark., 2014; Delbecq ve ark., 2014; Başer, 2015). Geliştirilen modeller, arazi fiyatını objektif ölçütlerle tespit etmede yardımcı olsa da, kullanılan değişkenlerin arazi fiyatı üzerine doğrudan ve dolaylı etkilerini veren sonuçları içermemektedir.

$\mathrm{Bu}$ araştırmada, arazi fiyatını etkileyen değişkenlerin doğrudan ve dolaylı etkilerini ortaya koymak için, 1920 yılında Sewall Wright tarafından geliştirilen path analizi yöntemi kullanılmıştır. Path analizi, dişsal değişkenlerin içsel değişken/değişkenler üzerindeki etkileri doğrudan, dolaylı ve bunların toplamından ibaret olan toplam etki şeklinde tarif edebilen ve nihayetinde bu etkileri yol şemasında görselleştirip karmaşık etki sistemlerinin sunumunun kolaylaşmasına imkân sağlayan bir tekniktir (Oktay ve ark., 2012). Standardize edilmiş değişkenler arasındaki ilişki sistemlerini inceleyen bir analiz tekniği olarak da bilinen path analizi; birbirleriyle sebep-sonuç ilişkisi içinde olduğu düşünülen değişkenler arasındaki ilişkileri gösteren path diyagramlarının oluşturulması, değişkenler arasındaki doğrusal ilişkilerin derecesini gösteren korelasyon katsayılarının doğrudan ve dolaylı etkileri ile bileşik path katsayılarına ayrılarak analiz edilmesi ve sonuçların doğru bir şekilde yorumlanması işlemlerini kapsamaktadır (Tahtalı ve ark., 2011).

Path analiziyle, arazi fiyatını etkileyen faktörlerin dolaylı ve doğrudan etkilerinin belirlendiği herhangi bir araştırmaya rastlanmamıştır. $\mathrm{Bu}$ bakımdan araştırmanın, arazi değerlemeyle ilgili literatüre önemli katk1 sağlayacağı düşünülmektedir. Araştırmanın amacı, arazi fiyatını etkileyen faktörlerin fiyat üzerine doğrudan ve dolaylı etkilerini belirlemektir. Ayrıca araştırmayla, sadece arazi 1slahı gibi yatırımlarla gerçekleşen değer artışının değil, aynı zamanda ürün verimliliğgi artışından kaynaklanan değer artışının etkisi de ortaya konulmuştur.

\section{Materyal ve Yöntem}

Araştırmanın materyali, 2018'de Samsun ili Ladik ilçesinde son iki yılda arazi satın alan 56 tarım işletmesiyle yapılan anketlerden oluşmaktadır. Arazi satın alan işletmeler, Ladik Tapu Müdürlüğü'nün kayıtlarından tespit edilmiştir. Ayrıca; Tapu ve Kadastro Genel Müdürlüğü, Coğrafi Bilgi Sistemleri Şube Müdürlüğü'nün, web tabanlı parsel sorgu sistemindeki arazi parsellerine ait verilerden de yararlanılmıştır.

Araştırmada arazi fiyatını etkileyen değişkenler olarak; eğim, sulama, taşlılık, verim, arazinin köye ve ana yola uzaklığı ele alınmış, ayrıca bu değişkenler arasındaki korelasyon katsayıları tespit edilmiştir. Arazinin taşlılık durumu ve eğimiyle ilgili sınıflandırmalar, Toprak ve Arazi Sınıflaması Standartları Teknik Talimatı esas alınarak oluşturulmuştur (Anonim, 2018). Buna göre arazi 
yüzeyinin \%10'una kadar taşlı olması durumunda, tarımsal üretimi aksatmayacağından arazi taşsız olarak kabul edilmiştir. Arazi yüzeyinin \% 10 ve daha fazlası taşla kaplı ise arazi taşlı sınıfında ele alınmıştır. Ayrıca \% 6 eğime kadar olan yerler eğimsiz, \% 6'dan fazla eğime sahip yerler eğimli arazi olarak sınıflandırılmıştır. Araştırmada buğdayın bölgedeki en yaygın ürün olmasından dolayı, verimlilik değişkeni buğday verimine endekslenmiştir. Buna göre arazi; buğday dekara verimi $0-200 \mathrm{~kg}$ ise çok düşük, 201-250 kg ise düşük, 251-375 kg ise orta, 376-500 kg ise yüksek, 500 kg'dan fazla ise çok yüksek olarak sınıflandırılmıştır.

Araştırmada en küçük kareler yöntemine göre oluşturulan regresyon analizinde, arazi fiyatı bağımlı değişken; eğim, sulama, taşlılık, verim, arazinin ana yola ve köye uzaklığı ise bağımsız değişkenler olarak ele alınmıştır. Path analizinde doğrudan etki katsayıları, standardize edilmiş regresyon katsayılarından oluşmaktadır. Bağımsız değişkenin, bağımlı değişken üzerindeki etkisini gösteren path katsayısı $\left(\mathrm{Pyx}_{\mathrm{k}}\right)$, Eşitlik 1'deki gibi hesaplanmaktadır (Mendes ve ark., 2005).

$$
P y x_{k}=b \frac{S x_{k}}{S_{y}}
$$

Eşitlik 1'de b, kısmi regresyon katsayısını; Sx, $\mathrm{X}$ özelliğine ait standart sapmayı; Sy, Y özelliğine ait standart sapmayı ifade etmektedir. Sx, Eşitlik 2; Sy, Eşitlik 3 yardımıyla hesaplanmıştır.

$$
\begin{aligned}
& S_{X}=\sqrt{\left(x_{k j}-\bar{x}_{k}\right)^{2}} \cdot \frac{1}{n}=\sqrt{\left(\sum x_{k j^{2}}-\frac{\left(\sum x_{k j}\right)^{2}}{n}\right)} \cdot \frac{1}{n}=\sqrt{S_{x x_{k}}} \\
& S_{y}=\sqrt{(Y-\bar{Y})^{2}} \cdot \frac{1}{n}=\sqrt{\left(\sum Y^{2}-\frac{\left(\sum Y\right)^{2}}{n}\right)} \cdot \frac{1}{n}=\sqrt{S_{y y}}
\end{aligned}
$$

Tüm değişkenlerin standardize edildiği analizde, path katsayılarının hesaplanmasında Eşitlik 4'te verilen matristen yararlanılmıştır (Topal ve ark., 2008).

$$
\left[\begin{array}{l}
P_{Y X_{1}} \\
P_{Y X_{2}} \\
P_{Y X_{3}} \\
P_{Y X_{4}} \\
P_{Y X_{5}} \\
P_{Y X_{6}}
\end{array}\right]=\left[\begin{array}{cccccc}
1 & r x_{1} x_{2} & r x_{1} x_{3} & r x_{1} x_{4} & r x_{1} x_{5} & r x_{1} x_{6} \\
r x_{2} x_{1} & 1 & r x_{2} x_{3} & r x_{2} x_{4} & r x_{2} x_{5} & r x_{2} x_{6} \\
r x_{3} x_{1} & r x_{3} x_{2} & 1 & r x_{3} x_{4} & r x_{3} x_{5} & r x_{3} x_{6} \\
r x_{4} x_{1} & r x_{4} x_{2} & r x_{4} x_{3} & 1 & r x_{4} x_{5} & r x_{4} x_{6} \\
r x_{5} x_{1} & r x_{5} x_{2} & r x_{5} x_{3} & r x_{5} x_{4} & 1 & r x_{5} x_{6} \\
r x_{6} x_{1} & r x_{6} x_{2} & r x_{6} x_{3} & r x_{6} x_{4} & r x_{6} x_{5} & 1
\end{array}\right]^{-1} \quad x \quad\left[\begin{array}{l}
r_{Y X_{1}} \\
r_{Y X_{2}} \\
r_{Y X_{3}} \\
r_{Y X_{4}} \\
r_{Y X_{5}} \\
r_{Y X_{6}}
\end{array}\right] \quad \text { (4) }
$$

Matriste $P_{Y X i}$, bağımlı ve bağımsız değişkenler arasındaki path katsayılarını (doğrudan etkileri), $r_{\text {xixj }} P_{Y X i}$ i'nci bağımsız değişkenin j'nci bağımsız değişken üzerinden bağımlı (Y) değişkene etkisini (dolaylı etkileri) göstermektedir. Denklemdeki $r_{x i x j}$, pearson korelasyon katsayısını ifade etmektedir. Doğrudan ve dolaylı etkilerin toplamı korelasyon katsayısını vermektedir. Doğrudan ve dolaylı etkilerin, korelasyon katsayısına oranlanmasıyla etkilerin oransal ağırlıkları hesaplanmıştır.
Araştırmada bağımlı ve bağımsız değişkenler arasındaki doğrudan ve dolaylı ilişkilerin, şematik olarak gösterilmesinde path diyagramindan yararlanılmıştır. Diyagramda tek yönlü oklar, bağımsız değişkenden bağımlı değişkene doğru çizilen doğrudan etkileri göstermektedir. Bağımsız değişkenler arasındaki oklar ise, çift yönlü olarak çizilmekte ve bunlar değişkenler arasındaki korelasyon katsayılarını göstermektedir.

Bağımlı ve bağımsız değişkenler arasındaki korelasyon katsayılarının hesaplanmasında SPSS, path diyagramının oluşturulmasında ise Amos programı kullanılmıştır.

\section{Bulgular ve Tartışma}

İncelenen arazi parsellerinin satış fiyatı ortalama $3750 \mathrm{TL} \mathrm{da}{ }^{-1}$ iken, buğdaya endekslenmiş verim $405.05 \mathrm{~kg} \mathrm{da}^{-1}$ 'dır. Parsellerin köye ve ana yola uzaklığı, arazi değerini etkileyen önemli değişkenler arasında yer almaktadır. Parsellerin köye uzaklığ 1 ortalama 750, ana yola uzaklığ 1 ise 300 metredir. İncelenen parsellerin sadece \% 28.57'si sulanmaktadır. Parsellerin \% 64.29'unun eğimi \% 6'dan yüksek iken, \% 69.97'sinin yüzeyi $\% 10$ ve daha az taşla kaplıdır (Tablo 1).

Korelasyon analizi sonuçlarına göre, arazi fiyatı ile verim ve sulama arasında pozitif; taşlılık, eğim, köye ve ana yola uzaklık arasında ise negatif yönde ilişki vardır. Arazi fiyatıyla pozitif yönde en yüksek ilişkiye sahip değişken verim iken, negatif yönde en yüksek ilişkiye sahip değişken taşl1lık durumudur (Tablo 2).

Arazi fiyatının tahmin edildiği standardize edilmiş çoklu regresyon denklemi, " $Y=-0.169$ eğim +0.232 sulama -0.211 taşlılık +0.314 verim - 0.220 köye uzakllk - 0.180 ana yola uzaklık" şeklinde tahmin edilmiştir. Denklemde katsayılar standardize edildiği için sabit sayı sıfır olmaktadır. Eşitlikteki kısmi regresyon katsayıları, her bir değişkenin sonuç değişkenleri üzerine doğrudan etkilerini ifade etmektedir (Tahtalı ve ark., 2011). Standardize edilmiş kısmi regresyon katsayıları ile katsayıların önem düzeyleri Tablo 3 'te verilmiştir.

Path diyagramında doğrudan etkileri gösteren tek yönlü oklara göre, arazi fiyatı üzerine doğrudan etkisi en yüksek değişken verimdir. Verimi sırasıyla; sulama, köye uzaklık, taşlılık, ana yola uzaklık ve eğim durumu takip etmektedir. Değişkenlerin birbirlerine çizilen çift yönlü oklar, değişkenler arasındaki korelasyonu göstermektedir. Path diyagramındaki korelasyon katsayılarına göre, verim ile taşl1lık, verim ile sulama, taşlılık ile eğim arasında yüksek korelasyon söz konusudur (Şekil 1). 
Tablo 1. Parsellere ait tanımlayıcı istatistikler

\begin{tabular}{|c|c|c|c|c|}
\hline Değişkenler & Ortalama & Standart sapma & Minimum & Maksimum \\
\hline Arazi fiyat $\left(\mathrm{TL} \mathrm{da}^{-1}\right)$ & 3750.00 & 1430.00 & 850.00 & 7500.00 \\
\hline $\operatorname{Verim}\left(\mathrm{kg} \mathrm{da}^{-1}\right)$ & 405.05 & 70.10 & 200.00 & 610.00 \\
\hline Çok düşük $\left(0-200 \mathrm{~kg} \mathrm{da}^{-1}\right)(\%)$ & 7.14 & & & \\
\hline Düşük (201-250 kg da-1) (\%) & 5.36 & & & \\
\hline Orta $\left(251-375 \mathrm{~kg} \mathrm{da}^{-1}\right)(\%)$ & 16.07 & & & \\
\hline Yüksek (376-500 kg da $\left.{ }^{-1}\right)(\%)$ & 44.64 & & & \\
\hline Çok yüksek $\left(501+\mathrm{kg} \mathrm{da}^{-1}\right)(\%)$ & 26.79 & & & \\
\hline Köye uzaklık (m) & 750.00 & 650.10 & 5.00 & 2750.00 \\
\hline Ana yola uzaklık $(\mathrm{m})$ & 300.00 & 350.00 & 12.00 & 1500.00 \\
\hline \multicolumn{5}{|l|}{ Eğim durumu } \\
\hline Eğimsiz $(\leq \% 6)$ & 35.71 & & & \\
\hline Eğimli $(>\%$ 6) & 64.29 & & & \\
\hline \multicolumn{5}{|l|}{ Sulama durumu } \\
\hline $\operatorname{Var}(\%)$ & 28.57 & & & \\
\hline Yok $(\%)$ & 71.43 & & & \\
\hline \multicolumn{5}{|l|}{ Arazi taşlılık durumu } \\
\hline Taşsız $(\leq \% 10)$ & 69.97 & & & \\
\hline Taşlı (>\% 10) & 30.03 & & & \\
\hline
\end{tabular}

Tablo 2. Değişkenler arasındaki pearson korelasyon katsayıları

\begin{tabular}{lcccccc}
\hline Değiş̧kenler & Arazi fiyat1 & Eğim & Sulama & Taşlılık & Verim & Ana yola uzaklık \\
\hline Eğim & $-0.439^{* *}$ & & & & & \\
Sulama & $0.611^{* *}$ & -0.131 & & & & \\
Taşlılık & $-0.678^{* *}$ & $0.516^{* *}$ & $-0.416^{* *}$ & & & \\
Verim & $0.712^{* *}$ & $-0.271^{*}$ & $0.544^{* *}$ & $-0.630^{* *}$ & & \\
Ana yola uzaklık & $-0.302^{* *}$ & 0.021 & -0.103 & $0.233^{*}$ & -0.131 & \\
Köye uzaklık & $-0.481^{* *}$ & 0.190 & $-0.364^{* *}$ & 0.200 & $-0.316^{* *}$ & 0.020 \\
\hline
\end{tabular}

${ }^{*}: \mathrm{p}<0.05$ düzeyinde önemlilik, ${ }^{* *}: \mathrm{p}<0.01$ düzeyinde önemlilik

Tablo 3. Standardize edilmiş regresyon analizi sonuçları

\begin{tabular}{lcccccc}
\hline Parametreler & Ĕ̆im & Sulama & Taşl1lık & Verim & Köye uzaklık & Ana yola uzaklık \\
\hline Katsayılar $\left(\mathrm{b}_{1}\right)$ & -0.169 & 0.232 & -0.211 & 0.314 & -0.220 & -0.180 \\
Önem düzeyi $(\mathrm{P})$ & 0.028 & 0.004 & 0.030 & 0.001 & 0.002 & 0.007 \\
VIF $^{*}$ & 1.433 & 1.549 & 2.280 & 2.022 & 1.209 & 1.074 \\
\hline
\end{tabular}

*: Variance inflation factor (Varyans genişlik faktörü)

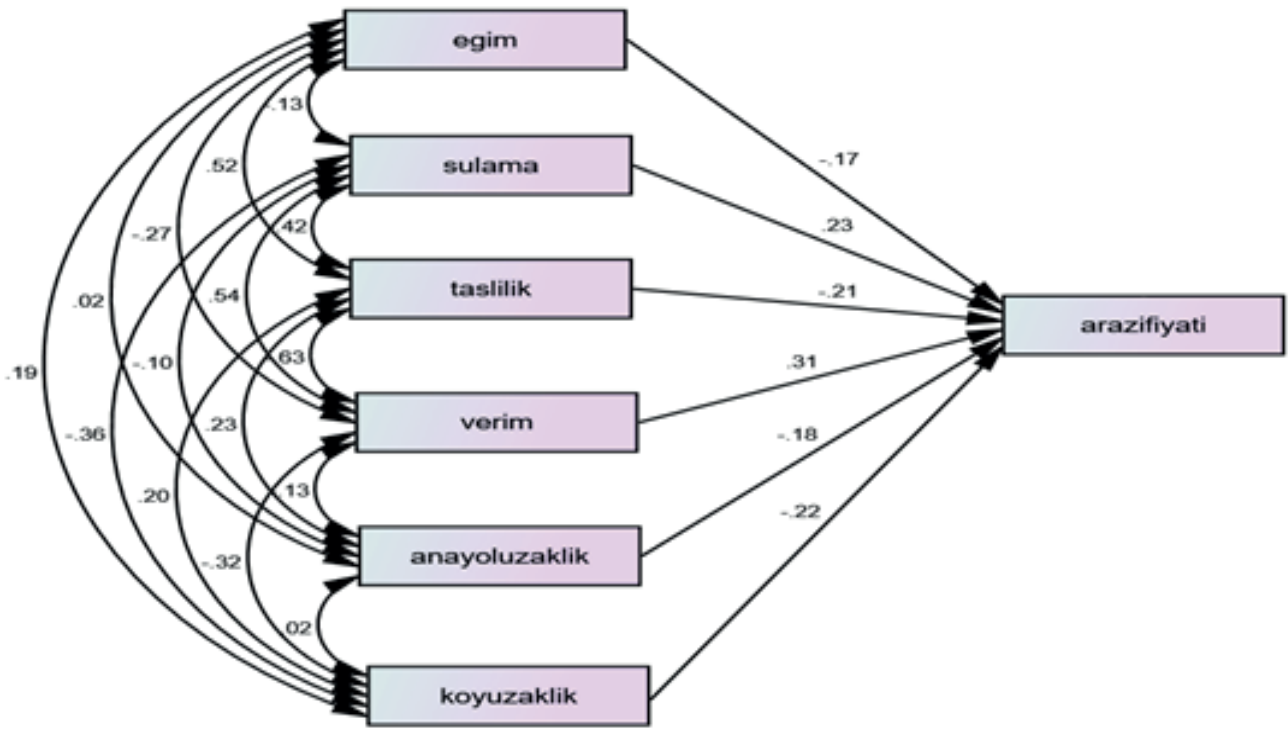

Şekil 1. Path diyagramı 
Araştırma sonuçları, arazi fiyatı üzerine negatif yönde en yüksek doğrudan etkiye sahip değişkenin köye uzaklık olduğunu göstermektedir. Buna göre, köye uzaklık arttıkça arazi fiyatı azalmaktadır. Araziye ait taşlılık, eğim, sulama ve verim gibi değişkenler ise arazi fiyatı üzerine daha çok dolaylı etkiye sahiptirler. Arazi fiyatını pozitif yönde etkileyen verimin arazi fiyatı üzerine doğrudan etkisi \% 44, dolaylı etkisi \% 56'dır. Arazi fiyatını pozitif etkileyen sulamanın ise doğrudan etkisi $\% 38$, dolaylı etkisi \% 62 'dir. Sulamanın arazi fiyatı üzerine olan \% 45'lik dolaylı etki, sulamanın verimi artırmasından kaynaklanmaktadır. Araştırmayla, arazi değerlemede yalnızca sulama yatırımıyla gerçekleşen değer artışının değil, aynı zamanda sulamanın verim üzerindeki dolaylı etkisinden kaynaklanan değer artışının da göz önüne alınması gerektiği ortaya konulmuştur. Negatif etkiye sahip değişkenlerden taşlılık durumunun doğrudan etkisi $\%$ 31, dolaylı etkisi \% 69 iken, dolaylı etkinin \% 42'si verimlilik azalışından kaynaklanmaktadır. Araştırma sonuçları, taşlılığın tarımsal üretimde büyük problem oluşturmasından dolayı, taşlı arazinin değerlemesinde verimden kaynaklı değer azalışının da göz önünde bulundurulması gerektiğini ortaya koymaktadır. Arazinin köye uzaklığı arazi fiyatını azaltan önemli bir unsurdur. Araştırmada köye uzaklığın arazi fiyatı üzerine doğrudan etkisi \% 46, dolaylı etkisi \%54 iken; dolaylı etkinin \% 38'i verimdeki azalma, \% 32'si ise sulama olanaklarının yetersiz olmasından dolayıdır.

Arazi değerini etkileyen önemli bir değişken de eğimdir. Eğimin fazla olması, arazinin işlenmesini güçleştirdiği için yapılan yatırımların maliyetini artırmaktadır. Araştırma sonuçlarına göre eğimin arazi fiyatı üzerine doğrudan etkisi \% 38, dolaylı etkisi \% 62 iken; dolaylı etkinin \% 40’', taşlılık problemi nedeniyle ortaya çıkmaktadır. Arazinin konumsal özelliklerinden olan ana yola uzaklığın, arazi fiyatına doğrudan etkisi \% 60, dolaylı etkisi ise $\% 40$ 'tır. Dolaylı etkinin $\% 40$ ', ana yola uzak arazinin taşlılık probleminden, \% 34'ü de ana yola uzak arazinin verimindeki azalmadan kaynaklanmaktadır (Tablo 4 ve 5). Arazi değerini etkileyen önemli değişkenler olarak, Roka ve Palmquist (1997) arazi büyüklüğü, toprak kalitesi, nüfus yoğunluğu ve misır verimi; Maddison (2000) iklim, toprak kalitesi, eğim ve arazinin yapısal özellikleri; Vural (2007) organik madde miktarı, toprak yapısı, verimlilik artışı ve arazi toplulaştırması; Donoso ve ark. (2013) tarımsal ve sulama altyapıları, toprak özelliği, nüfus yoğunluğu ve şehir merkezine mesafe; Öztürk Çoşar ve Engindeniz (2013) müştemilat durumu; Choumert ve Phelinas (2015) ise toprak kalitesi, arazinin konumu, pazarlara uzaklığı ve şehrin yakınında olması olarak ortaya koymuşlardır.

Tablo 4. Değişkenlerin dolaylı ve doğrudan etki katsayıları

\begin{tabular}{|c|c|c|c|c|c|c|c|c|c|}
\hline \multirow[b]{2}{*}{ Değişkenler } & \multicolumn{6}{|c|}{ Dolaylı etki } & \multirow[b]{2}{*}{ Toplam } & \multirow[b]{2}{*}{$\begin{array}{l}\text { Doğrudan } \\
\text { etki }\end{array}$} & \multirow[b]{2}{*}{$\begin{array}{c}\text { Korelasyon } \\
\text { katsay1sı }\end{array}$} \\
\hline & Eğim & Sulama & Taşl111k & Verim & $\begin{array}{l}\text { Ana yola } \\
\text { uzaklik }\end{array}$ & $\begin{array}{c}\text { Köye } \\
\text { uzaklık }\end{array}$ & & & \\
\hline Eğim & & -0.030 & -0.109 & -0.085 & -0.004 & -0.042 & -0.270 & $-0.169^{*}$ & $-0.439^{* *}$ \\
\hline Sulama & 0.022 & & 0.088 & 0.171 & 0.019 & 0.080 & 0.379 & $0.232^{* *}$ & $0.611^{* *}$ \\
\hline Taşlılık & -0.087 & -0.096 & & -0.198 & -0.042 & -0.044 & -0.467 & $-0.211^{*}$ & $-0.678^{* *}$ \\
\hline Verim & 0.046 & 0.126 & 0.133 & & 0.024 & 0.069 & 0.398 & $0.314^{* *}$ & $0.712^{* *}$ \\
\hline Ana yola uzaklık & -0.004 & -0.024 & -0.049 & -0.041 & & -0.004 & -0.122 & $-0.180^{* *}$ & $-0.302^{* *}$ \\
\hline Köye uzaklık & -0.032 & -0.084 & -0.042 & -0.099 & -0.004 & & -0.261 & $-0.220^{* *}$ & $-0.481^{* *}$ \\
\hline
\end{tabular}

${ }^{*}: \mathrm{p}<0.05$ düzeyinde önemlilik, ${ }^{* *}: \mathrm{p}<0.01$ düzeyinde önemlilik

Tablo 5. Değişkenlere ait dolaylı ve doğrudan etki oranları

\begin{tabular}{|c|c|c|c|c|c|}
\hline \multirow{2}{*}{ Değişkenler } & \multirow{2}{*}{$\begin{array}{c}\text { Korelasyon } \\
\text { katsay1s1 }\end{array}$} & \multicolumn{2}{|c|}{ Dolaylı etki } & \multicolumn{2}{|c|}{ Doğrudan etki } \\
\hline & & Katsayı & $(\%)$ & Katsayı & $(\%)$ \\
\hline Ĕgim & $-0.439^{* *}$ & -0.270 & 62 & $-0.169^{*}$ & 38 \\
\hline Sulama & $0.611^{* *}$ & 0.379 & 62 & $0.232^{* *}$ & 38 \\
\hline Taşlilık & $-0.678^{* *}$ & -0.467 & 69 & $-0.211^{*}$ & 31 \\
\hline Verim & $0.712^{* *}$ & 0.398 & 56 & $0.314^{* *}$ & 44 \\
\hline Ana yola uzaklık & $-0.302^{* *}$ & -0.122 & 40 & $-0.180^{* *}$ & 60 \\
\hline Köye uzaklık & $-0.481^{* *}$ & -0.261 & 54 & $-0.220^{* *}$ & 46 \\
\hline
\end{tabular}

${ }^{*}: \mathrm{p}<0.05$ düzeyinde önemlilik, ${ }^{* *}: \mathrm{p}<0.01$ düzeyinde önemlilik

Benzer değişkenlerin kullanıldığı bu araştırmada ise, araziye ait özelliklerin yalnızca doğrudan etkileri değil, aynı zamanda dolaylı etkilerine de yer verilmiştir.

\section{Sonuç ve Öneriler}

Araştırmada arazi fiyatının beklenildiği gibi verim ve sulamayla pozitif yönde, köye ve ana yola 
uzaklık, taşlılık ve eğimle negatif yönde ilişkili olduğu tespit edilmiştir. Tarımsal gelire doğrudan etki eden verimlilik, arazi fiyatıyla en yüksek korelasyona sahip değişkendir. Bununla birlikte sulama, köye uzaklık ve eğim gibi değişkenler ürün verimini etkilediği için, arazi fiyatına dolaylı olarak etki etmektedirler. Araştırmada, arazi fiyatı üzerine doğrudan etkiye sahip en önemli değişken \% 60'la ana yola uzaklık iken; dolaylı olarak en yüksek etkiye sahip değişken, \% 69'la arazinin taşl1lık durumudur. Arazideki taşl1lık durumunun, verimlilik üzerindeki negatif etkisinin \% 42'si verimlilik azalışından kaynaklanmaktadır.

Tarım arazisi, bazı fiziksel ve konumsal özellikleri içerisinde barındıran bir gayrimenkuldür. Arazi fiyatı; kamulaştırma, toplulaştırma çalışmaları ve banka ipoteği gibi konularda kamu ve özel sektörü yakından ilgilendirmektedir. Farklı birçok amaç için değerleme çalışmasına konu olan tarım arazisi; eğim, taşlılık, verim gibi bazı özelliklere sahiptir. Her bir arazi parselinin kendine has bu özellikleri arazi fiyatını artırmakta ya da azaltmaktadır. Türkiye'de son yıllarda yapılan altyap1 ve üstyap1 yatırımları nedeniyle arazi değerleme uygulamaları artmıştır. Ancak bilirkişi raporlarındaki eksik ve yanlışlıklardan dolayı, yapılan itirazlar da arttı̆̆ 1 için davaların maliyeti artmakta ve yatırımların tamamlanması gecikmektedir. $\mathrm{Bu}$ bakımdan arazi fiyatını doğrudan ve dolaylı etkileyen faktörlerin tespit edilmesi, arazi değerleme çalışmalarında bilirkişiler için önemli bir kaynak ve yol gösterici olacaktır. Örneğin; sulamanın tek başına arazinin fiyatını artıran bir unsur olarak görülmemesi, aynı zamanda sulama üzerine dolaylı etkisi olan verimlilik artışının da göz önünde bulundurulması doğru bir yaklaşım olacaktır. Arazi fiyatını etkileyen değişkenlerin, doğrudan ve dolaylı etkilerini oransal olarak ortaya koyan araştırmaların artırılması, kamu kurumları ve özel sektörün arazi değerlemeyle ilgili çalışmalarına yardımcı olacak ve değerlemede objektifliğin sağlanmasına önemli katkı sağlayacaktır.

\section{Kaynaklar}

Anonim, 1983. Kamulaştırma Kanunu. Kanun Numarası: 2942, Kabul Tarihi: 04/11/1983, 08/11/1983 Tarih ve 18215 Sayı No'lu Resmi Gazete (Değişik: 24/4/20014650/6 md.).

Anonim, 2018. Toprak ve Arazi Sinıflaması Standartları Teknik Talimatı. Tarım ve Orman Bakanlığı, (http://www.tarim.gov.tr/Belgeler/Mevzuat/Talimatl ar/ToprakAraziSiniflamasiStandartlariTeknikTalima ti vellgiliMevzuat_yeni.pdf), (Erişim tarihi: 16.07.2018).

Başer, U., 2015. Samsun ili Lâdik ilçesinde arazi fiyatını etkileyen faktörlerin belirlenmesi. Yüksek lisans tezi,
Ondokuz Mayıs Üniversitesi, Fen Bilimleri Enstitüsü, Samsun.

Borchers, A., Ifft, J., Kuethe, T., 2014. Linking the price of agricultural land to use values and amenities. American Journal of Agricultural Economics, 96(5): 1307-1320.

Choumert, J., Phelinas, P., 2015. Determinants of agricultural land values in Argentina. Ecological Economics, 110: 134-140.

Delbecq, B.A., Kuethe, T.H., Borchers, A.M., 2014. Identifying the extent of the urban fringe and its impact on agricultural land values. Land Economics, 90(4): 587-600

Donoso, G., Cancino, J., Foster, W., 2013. Farmland values and agricultural growth: the case of Chile. Economía Agraria Y Recursos Naturales, 13(2): 3352.

Hurma, H., 2007. Çevre kalitesinin tarımsal arazi değeri üzerine etkilerinin analizi: Trakya örneği. Doktora tezi, Namık Kemal Üniversitesi, Fen Bilimleri Enstitüsü, Tekirdağ.

Isgin, T., Forster, D.L., 2006. A hedonic price analysis of farmland option premiums under urban influences. Canadian Journal of Agricultural Economics, 54(3): 327-340.

K1lıç, O., 2011. Kamulaştırma davalarında arsa-arazi ayrımı. Akdeniz Üniversitesi Ziraat Fakültesi Dergisi, 24(1): 15-18.

Kılıç, O., 2011. Tarım arazisi için kapitalizasyon oranının hesaplanmas1. Anadolu Tartm Bilimleri Dergisi, 26(2): 181-187.

Kuethe, T.H., Ifft, J., Morehart, M., 2011. The influence of urban areas on farmland values. Choices, 26(2).

Maddison, D., 2000. A hedonic analysis of agricultural land prices in England and Wales. European Review of Agriculture Economics, 27(4): 519-532.

Mendes, M., Karabayır, A., Pala, A., 2005. Path analysis of the relationships between various body measures and live weight of American Bronze Turkeys under the three different lighting programs. Tartm Bilimleri Dergisi, 11(2): 184-188.

Oktay, E., Akınc1, M.M., Karaaslan, A., 2012. Yol analizi yardımıyla dersler arasındaki etkileşimin araştırılması: Atatürk Üniversitesi İktisadi ve İdari Bilimler Fakültesi İşletme Bölümünde okutulan dersler üzerine bir uygulama. Atatürk Üniversitesi İktisadi ve İdari Bilimler Dergisi, 26(3-4): 67-83.

Öztürk Çoşar, G., Engindeniz, S., 2013. Tarım arazisi değerlerinin hedonik analizi: İzmir'in Menemen ilçesi örneği. Ege Üniversitesi Ziraat Fakültesi Dergisi, 50(3): 241-250.

Rehber, E., 2012. Tarımsal Değerleme ve Bilirkişilik. Üçüncü Baskı, Ekin Yayınevi, Bursa.

Roka, F.M., Palmquist, R.B., 1997. Examining the use of national databases in a hedonic analysis of regional farmland values. American Journal of Agricultural Economics, 79(5): 1651-1656.

Sklenicka, P., Molnarova, K., Pixova, K.C., Salek, M.E., 2013. Factors affecting farmland prices in the Czech Republic. Land Use Policy, 30(1): 130-136. 
Tahtalı, Y., Sahin, A., Ulutas, Z., Sirin, E., Abac1, S.H., 2011. Esmer 1rk1 sığırlarda süt verimi üzerine etkili faktörlerin path analizi ile belirlenmesi. Kafkas Üniversitesi Veteriner Fakültesi Dergisi, 17(5): 859864.

Topal, M., Emsen, B., Dodologlu, A., 2008. Path analysis of honey yield components using different correlation coefficients in caucasian honey bee. Journal of Animal and Veterinary Advances, 7(11): 1440-1443.

Vural, H., 2007. Türkiye'de arazilerin klymet takdiri üzerine kantitatif bir yaklaşım: Bursa ili Karacabey Ovas1 örneği. Uludă̆ Üniversitesi Ziraat Fakültesi Dergisi, 21(2): 13-20. 